\title{
Contribution of Satellite Altimetry Data in the Environmental Geophysical Investigation of the Northern Egyptian Continental Margin
}

\author{
Hamdy Ahmed Mohamed Aboulela \\ Marine Science Department, Faculty of Science, Suez Canal University, Ismailia, Egypt \\ Email: aboulel1_004@yahoo.co.uk
}

Received March 20, 2012; revised April 21, 2012; accepted May 20, 2012

\begin{abstract}
The northern Egyptian continental margin is characterized by interesting tectonic settings as well as trade and industry district in Egypt. In the current study, the contribution role of satellite altimetry gravity data in the Environmental geophysical investigation is presented to give a complete view of the marine gravity field of the study area. The satellite data showed only minor deviations in some partial regions of the area investigated such as Nile Deep Sea Fan, Levant Basin, Eratosthenes Seamount and Herodotus basin. The interpretations of the entire data illustrated that the differences between the satellite and the shipboard data were small in some regions particularly near to land. Furthermore, a number of strong deviations in some regions were spatially correlated with bathymetric depth together with the appearance of geological structures.
\end{abstract}

Keywords: Northern Egyptian Continental Margin; Satellite Altimetry Data; Free-Air Gravity

\section{Introduction}

The Earths surface has been monitored for nearly twenty years from satellites altimeters. Global mapping of the Earth gravity fields from different data sources has previously been presented by [1-4]. The first gravity field from the full ERS-1 geodetic mission were presented by [5]. Additionally, Satellite altimetry has enhanced our understanding of marine gravity, seafloor bathymetry and ocean circulation. Two satellites have been operated in geodetic mission configurations. GEO-SAT (1985-1986) where the satellite was operated in a non-repeating orbit, which yielded a very dense, though not completely homogeneous coverage of observations, and ERS- 1 which covers all oceans between -82 and +82 latitudes and provides a very dense and homogeneous coverage [4].

The concept of determining marine gravity anomalies from satellite radar altimetry is as follows: The altimeter essentially measures the distance between the satellite and the sea surface along the nadir using pulse-limited radar at a series of footprints along the sub-satellite tracks [6]. After modeling tidal effects and applying geophysical corrections, these measurements are then averaged (stacked) to give the mean shape of the sea surface with respect to a prescribed reference ellipsoid, knowing the position of the satellite from tracking, dy- namic orbit modeling or both. To a first coarse approximation, the mean sea surface coincides with the geoid. However, these two surfaces depart by up to $\sim 2 \mathrm{~m}$ due to sea surface topography, which is caused by oceanographic effects [7]. Therefore, techniques to model and/ or mitigate the effects of sea surface topography from the altimeter measurements form an integral part of estimating marine gravity anomalies from satellite altimetry.

In the present work, the marine gravity data derived from satellite altimetry have been used in an evaluation of the gravity field of the northern Egyptian continental margin (Figure 1). This area has been chosen as a site of case study for many reasons. Firstly, this region is of great importance from the economic point of view as a productive oil zone in Egypt which makes quite significant to recognize off-shore sedimentary basins and nearsurface geological structures. Furthermore, this region is characterized by remarkable tectonic settings accompanied by active tectonic activity processes. These tectonics have been interesting for many authors who studied rifting mechanisms in relation to the seismic activity in this region [8-10]. The aim of this study is to highlight the contribution of satellite altimetry gravity data in geophysical investigation, and give a complete view of the marine gravity field of the study area. In addition, a comparison of the result of the shipboard marine Free-air 


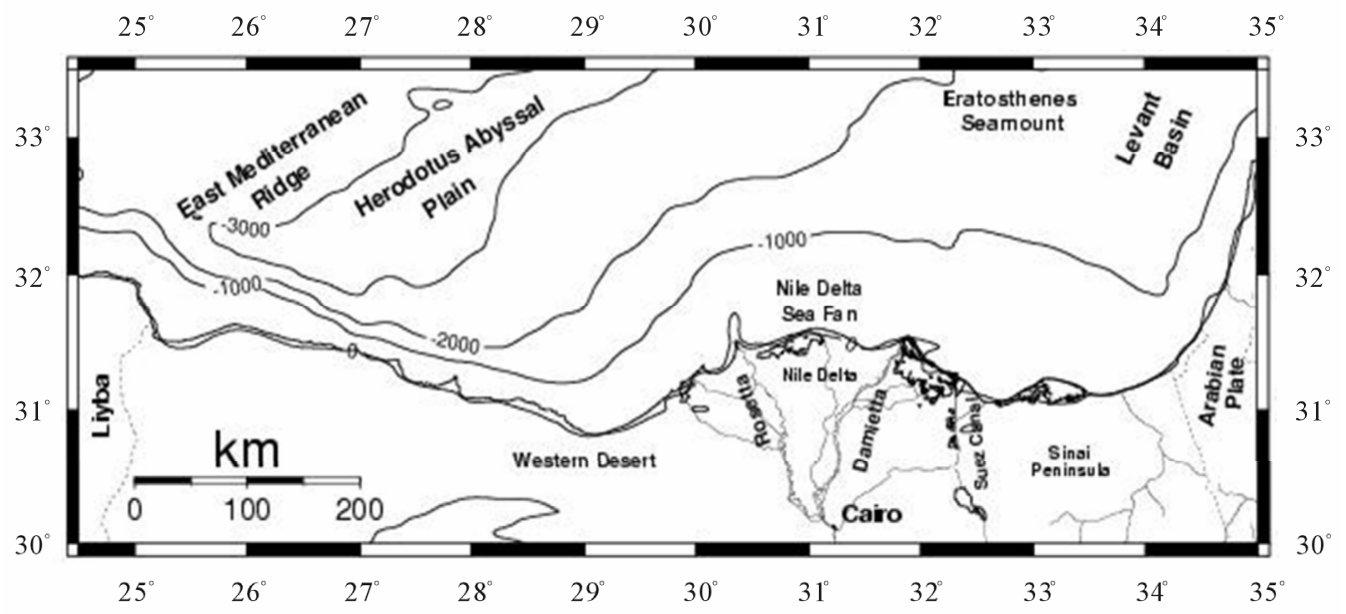

Figure 1. Location map of the area investigated.

gravity data with the gravity data derived from satellite altimetry of the study area will be presented.

\section{Geological Background}

The regional geology of the study area was the subject of many investigations since it forms a significant structural unit in tectonics framework of northern Egyptian continental margin and Eastern Mediterranean. In view of the available literature on the geology and tectonic of the mentioned area such as those published by [8-24], and other investigators of the study area and its surroundings, it can be stated that:

- The main Bathymetric and margin topographic features are relatively wide and show a discrepancy in width from east to west of the coastal zone and adjacent sea floor as shown in Figure 2.

- The Egyptian continental margin is located to the south of the folded arc forming the Mediterranean ridge, where the sea floor is occupied by the Nile Deep Sea Fan, Levant Basin, Eratosthenes Seamount and Herodotus basin.

- The Egyptian continental margin bordering the Eastern Mediterranean Sea is characterized by a narrow continental shelf extending from the shoreline seaward to the shelf edge at about $15-20 \mathrm{~km}$. However, the shelf in the region between Rosetta mouth and Bardawil Lake becomes wider, where it ranges in excess of $70 \mathrm{~km}$ [25].

- The Mediterranean ridge, Levant Basin and Nile Deep Sea Fan are the major morphostructral domains in study area. The Mediterranean ridge is a long accretionay prism between Africa and southern Europe, consisting of sediments which are scrapped off from the subducting plate [20].

- The Nile Deep Sea Fan is bounded by the Dead Sea shear zone to the east and the Cyprus convergent zone and the Mediterranean Ridge to the north. Three major morphological structures and sedimentary provinces characterize the Nile Deep Sea fan (eastern, central and western) as pointed by $[13,16,18,19]$.

- The Nile Delta Fan is considered as a large hinge zone that consists of several southward half-grabens. These grabens are deformed and bounded by eastwest-orientated northward-dipping listric faults [9].

- The Fan is the largest sedimentary clastic accumulation within the southern Eastern Mediterranean Sea [25]. Generally, the total thickness of sediments on the Egyptian continental margin could exceed $9 \mathrm{~km}$ as suggested by Mascle et al., (2000) [18,19].

- The Egyptian continental shelf in the western part is affected by a series of WNW trending faults. The present steep faulted continental slope which has a rectilinear WNW orientation varies in width from 34 to $56 \mathrm{~km}$ of the Western Desert of Egypt to about 20 $\mathrm{km}$ seaward of the Delta [23].

- In the area immediately seaward of the Nile Delta Fan, the slope shows a fairly well developed stratification with many closely spaced normal faults. In principle, the continental margin can be considered as a weakness zone which experienced thinning of the crust during the Triassic period. This zone of transition between the faulted continental crust might be predestined by its $110^{\circ} \mathrm{N}-120^{\circ} \mathrm{E}$ orientation, to be reactivated with dextral strike slip and reverse components [24].

- According to $[11,22]$ the northern Egypt underwent three subsequent tectonic phases from early Mesozoic to present. The present day stress regime affecting the Egyptian continental margin, where maximum compressional stress is oriented $\mathrm{N}$ to $\mathrm{N} 30^{\circ} \mathrm{W}$, comprise normal faults trending nearly with this direction and reactivated reverse faults in the perpendicular direction $[15,24]$. 


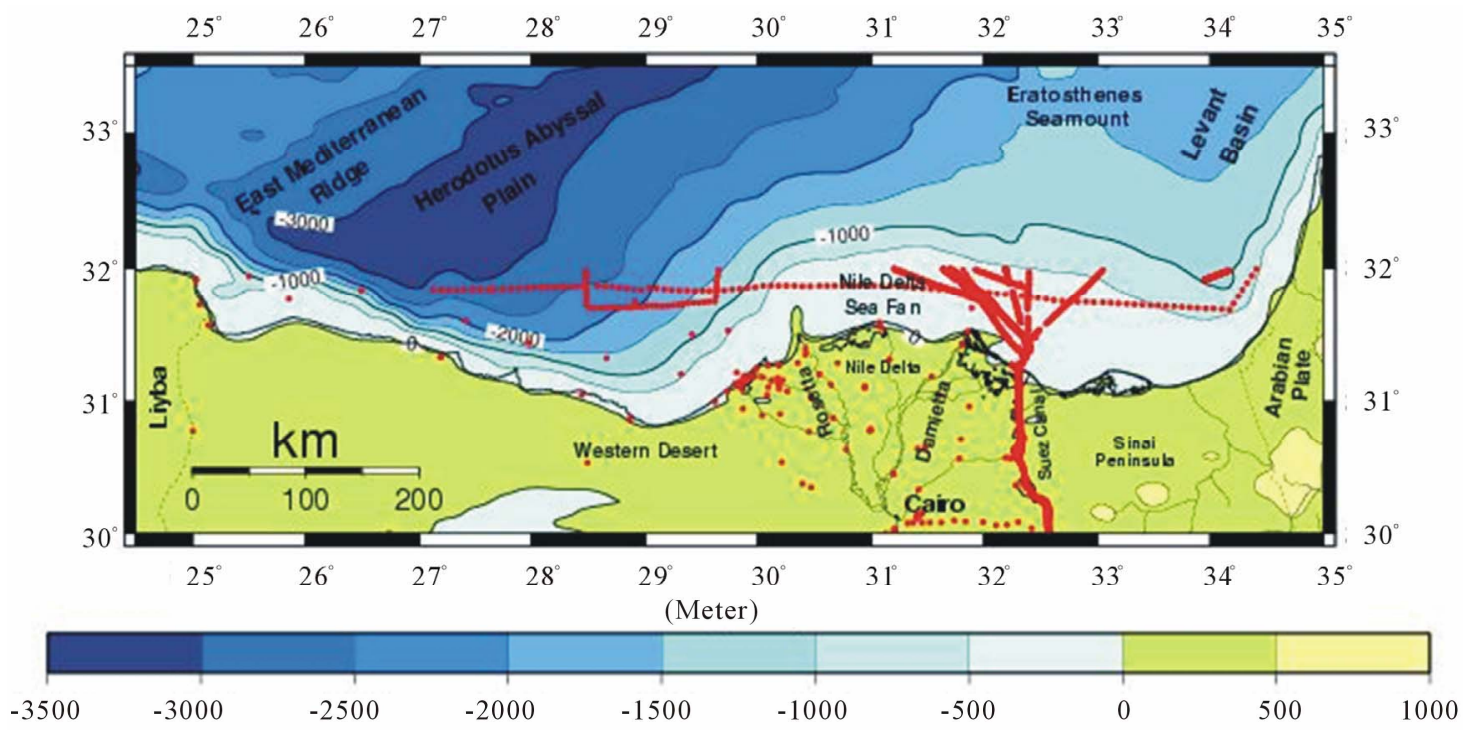

Figure 2. Bathymetric and topographic features pattern map of the study area. The red thick line represents the location of data sources acquired from Bureau Gravity International data base (B.G.I.); and ETOPO (Eastern Topographics) respectively.

\section{The Data Set}

The available marine gravity field data were derived from satellite altimetry. The mentioned data were obtained from: Sandwell's version 10.1 global grid [4], and KMS99, KMS02 [26]. For two decades, Sandwell of Scripps Institute of Oceanography, California, USA, has produced global gravity anomalies from multi-mission satellite altimetry. Sandwell's version 10.1 global grid of marine gravity anomalies is the most recent in this series, with the developments leading to the model reported in $[4,27]$.

The version 10.1 global grid is available on 1 or 2 arc-minute spatial resolution grids from http://topex.ucsd. edu/marine_grav/mar_grav.html. Only the 2 arc-minute grid is used in this study so as to be compatible with KMS grids. Furthermore, for nearly a decade, Andersen and Knudsen of Kort-og Matrikstyrelsen (KMS), Copenhagen, Denmark, have computed global marine gravity anomalies from multi-mission satellite altimetry. The progressive developments in their techniques are reported for example in $[1,26]$.

The KMS02 and KMS99 gravity anomaly grids are the most recent in this series and result from refinements in the techniques described by Andersen and Knudsen, 1998. Both grids are supplied at a 2 arc-minute by 2 arcminute spatial resolution, and are available in the public domain via anonymous ftp from ftp.kms.dk/GRAVITY.

The Free-air gravity data based on satellite altimetry from Sandwell's version 10.1 global grid was carried out relative to the altimetry data reduction to gravity data. The altimetry data are separated into ascending and descending profiles for each repeat cycle and differentiated in the along-track direction to obtain along-track vertical deflections (geoid slopes). The vertical deflections for all the repeat cycles are then averaged into a single ascending and descending profile which are combined to produce grids of the eastern and northern components of vertical deflection. These grids are used to compute both gravity anomaly and vertical gravity gradient grids [4]. The marine gravity field derived from satellite altimetry by Sandwell's version 10.1 global grid shows a wavelength of 10 to $15 \mathrm{~km}[4,28]$. The Free-air gravity anomaly mapping of the KMS99; KMS02 gravity field was carried out relative to the geoid using the GRAV-SOFT software. The processing of data and conversion of observations into gravity field were carried out in small cells of size 2 latitude by 10 longitude and sea surface variability [29]. The selection of such small sub-areas was essential to the modeling of orbit errors KMS99 and KMS02 grids is a further fine-tuning of the filter characteristics, both in gridding of geoid height to gravity anomalies. Satellite altimeter Free-air gravity anomalies maps of the study area is given in Figures 3-5 based on satellite data from [28] and KMS99, KMS02 respectively.

The accessible shipboard Bouguer and Free-air gravity data used in this study were obtained from Bureau Gravity International data base (B.G.I.). These data have been combined with data collected from the Egyptian General Petroleum Company (EGPC, 1980) which was published as a set of Bouguer gravity anomaly maps of Egypt at 1:500,000 scale by compiling all available gravity data (Figure 6). A simplified and redrawn version of new Free-air gravity anomaly map was produced to carry out 


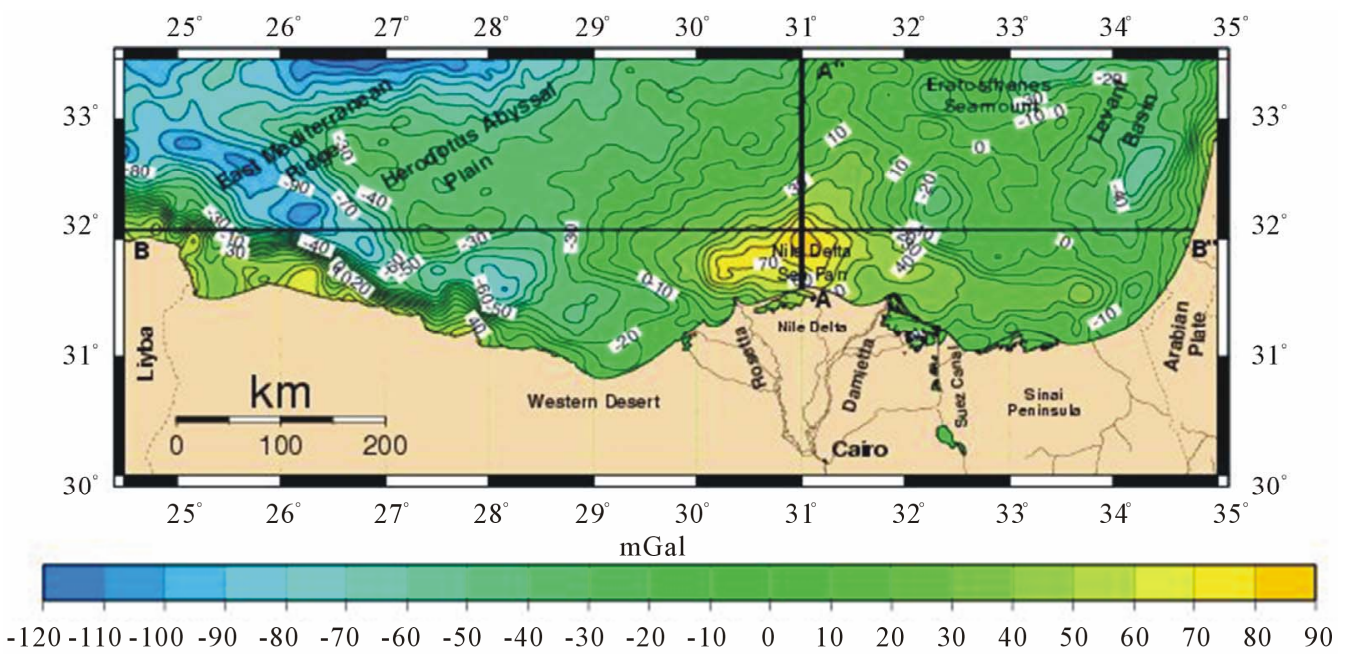

Figure 3. Free-Air gravity anomaly map based on the satellite data. Satellite data obtained from Sandwell et al., 1997. The black thick red line represents location of the profiles A-A"; and B-B".

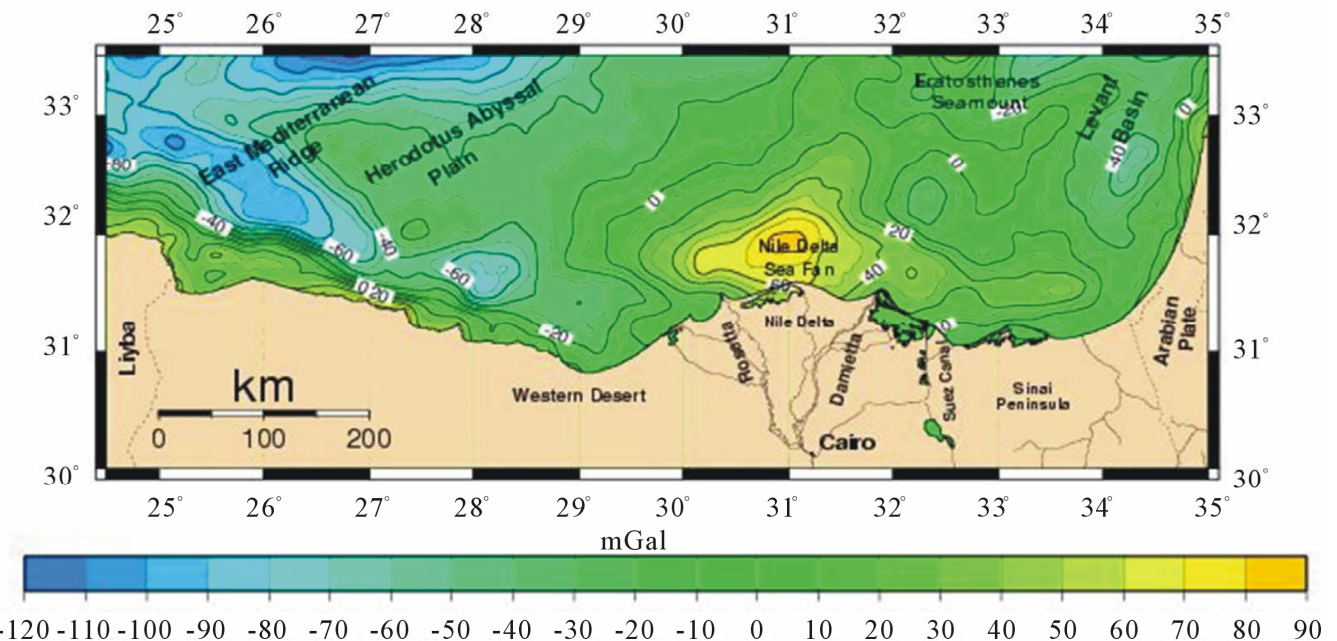

Figure 4. Free-Air gravity anomaly map based on the KMS99 satellite data. Satellite data obtained from Andersen and Knudsen, 1998.

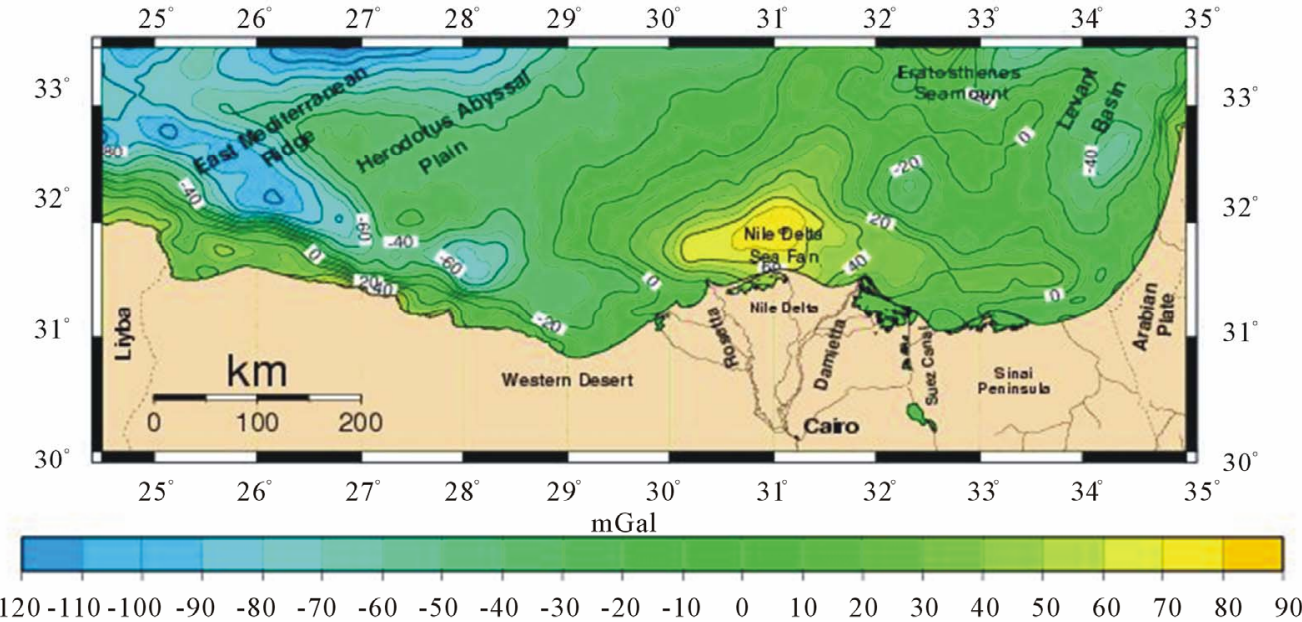

Figure 5. Free-air gravity anomaly map based on the KMS02 satellite data. Satellite data obtained from Andersen and Knudsen, 1998. 


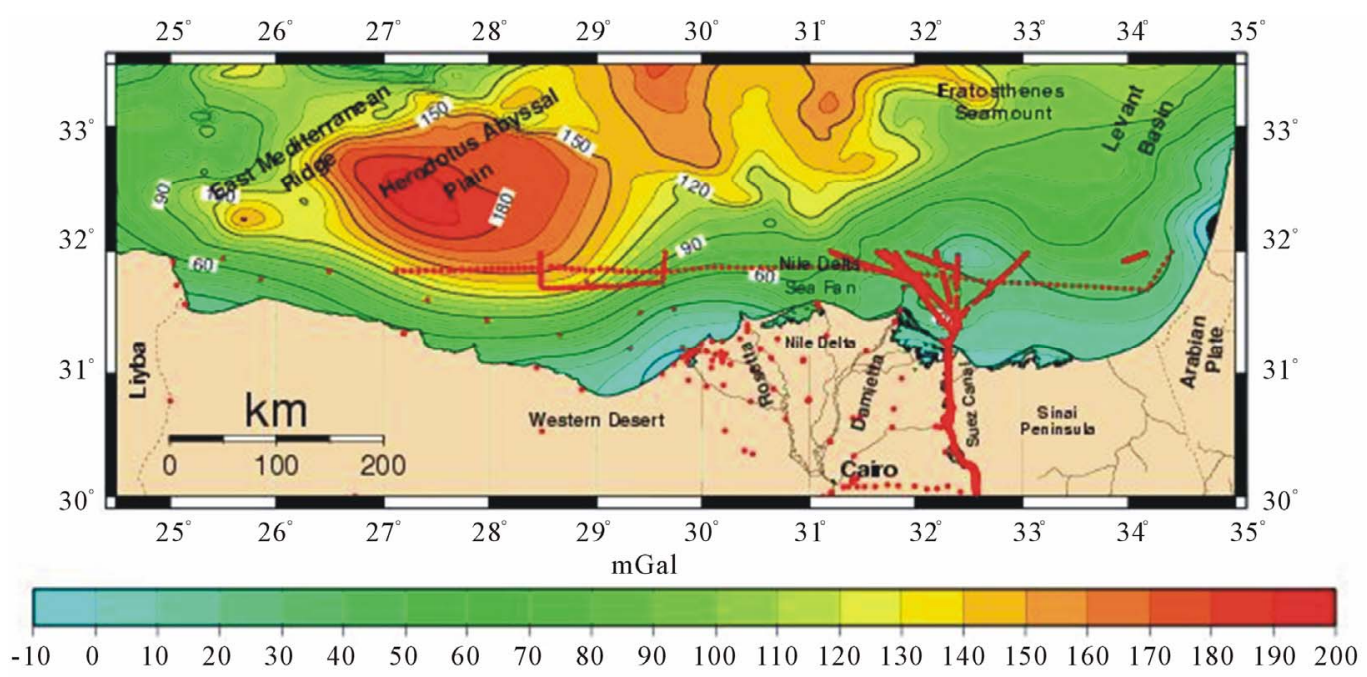

Figure 6. Bouguer gravity anomaly map of the northern Egyptian continental margin. Contour interval is $10 \mathrm{mGal}$. The Red thick line represents the location of data sources acquired from Bureau Gravity International data base (B.G.I.) and Egyptian General Petroleum Company (EGPC, 1980).

a quantitives interpretation of the area investigated (Figure 7). To gain knowledge of the geographic setting and elucidate of the relief of morphotectonic of the area investigated, several profiles were acquired from (B.G.I.). These data were combined with the available Etopo data (Eastern Topographics) to construct the main features of the Bathymetric and topographic map of the area investigated as shown in Figure 2.

\section{Methodology and Tools}

As a general rule, the function of geoid in environmental geophysical investigation is a topic of recent interest for many years. Geoid is a surface of constant potential energy that coincides with mean sea level over the oceans and represents the mean sea level in land. It defines the figure of the Earth and undulates due to spatial variations in the Earth's gravity field [30].

Theoretically, geoid can be determined from different types of input data. One of the possibilities is the gravimetric solution, according to the well-known Stoke's formula for the geoid undulation relative to the reference ellipsoid.

$$
N=R / 4 \pi \gamma \iint \Delta g_{i} S\left(\psi_{i}\right) \mathrm{d} \sigma
$$

where $S(\psi)$ is the Stokes function, $R$ is the mean radius of the Earth and $\sigma$ denotes the Earth's surface [4]. By using Equation (1), the geoid undulation $(N)$, representing the physical figure of the Earth, can be determined from the gravity observations [4].

Two particular distance dimensions are necessary to obtain the geoid in satellite altimetry data. First, the ellipsoid height $h$ is measured by tracking the satellite over globally distributed control stations. Second, the height of the satellite above the ocean surface $H$ is measured with a microwave radar altimeter [4].

The reasons behind the interests of converting the observed geoid into gravity anomaly are subsequent, the converted gravity anomaly enhances the detection of small scale features of the ocean floor while the geoid reflects deeply buried density variations, as well as satellite gravity measurements can be compared and combined with marine gravity observations. The geoid can be transformed into gravity anomaly by using inverse Stoke's formula (Equation (1)), or by taking the derivatives of the geoid using Laplace's equation [4]. Gravity anomaly $\Delta g$ associated with geoid height $N$ with a wavelength $\lambda$ is given by

$$
\Delta g=2 \pi \gamma N / \lambda
$$

where $\gamma=980,000 \mathrm{mGal}$ is the average gravity of the Earth. This equation indicates that the gravity anomaly of $10 \mathrm{mGal}$ and a wavelength of $10 \mathrm{~km}$ is associated with geoid undulation of $16 \mathrm{~mm}$. This shows the precision needed for the geoid determination in order to compute gravity anomalies useful for environmental geophysical applications.

As mentioned above, there are several methodology and tools to compute gravity anomalies from satellite altimetry such as: Method 1: Gravity anomalies from point-mass models; Method 2: Gravity anomalies from geoid heights using an inverse Stokes integral; Method 3: Gravity anomalies from vertical deflections using an inverse Vening-Meinsz integral; and Method 4: Gravity anomalies from vertical deflections via Laplace's equation $[31,32]$. Also there are some significant differences between marine gravity anomalies computed by different groups from satellite rader altimetry (e.g. Sandwell's 


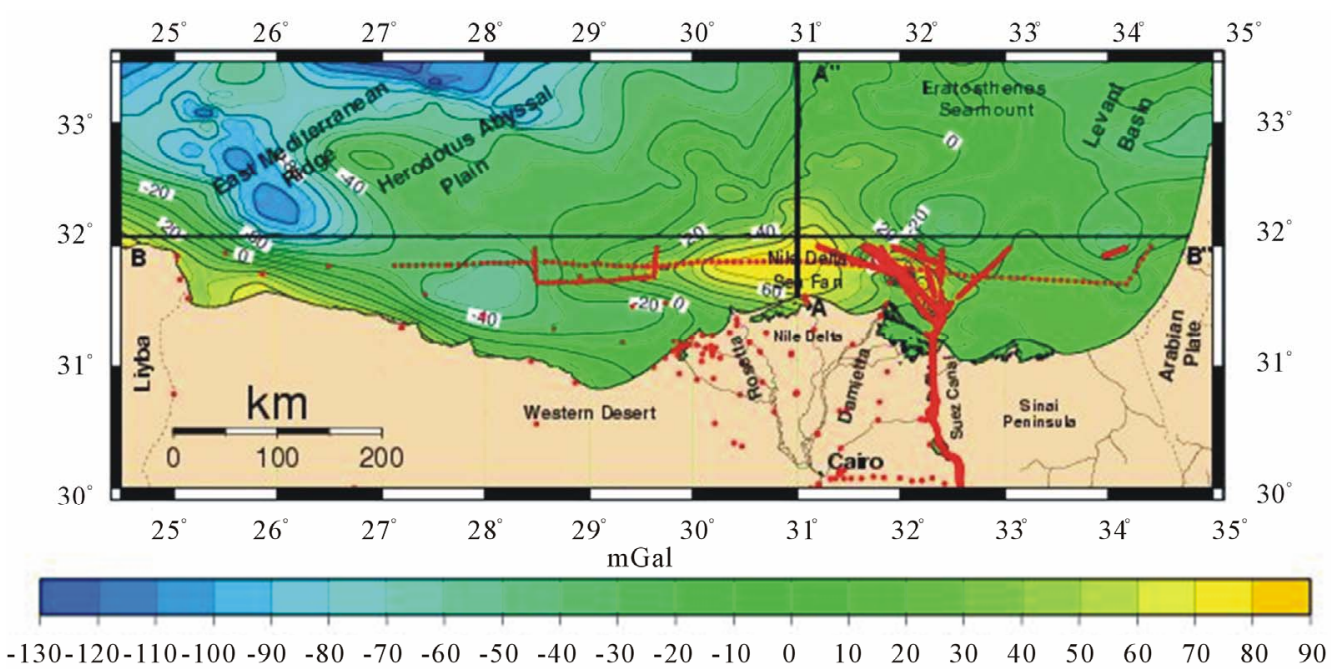

Figure 7. Free-air gravity anomaly map of the northern Egyptian continental margin. Contour interval is $10 \mathrm{mGal}$. The Red thick line represents the location of data sources acquired from Bureau Gravity International data base (B.G.I.) and Egyptian General Petroleum Company (EGPC, 1980). The black thick red line represents location of the profiles A-A"; and B-B".

version 10.1 global grid and KMS grids satellite altimetry). These tend to become larger in coastal regions, which is due to the numerous problems associated with correcting altimeter data in these regions. Therefore, these data should be used with extreme caution in these regions. Since the altimeter grids are derived from predominantly the same altimeter data sources (mostly GEOSAT and ERS-1), the differences are due to the data treatment (notably outlier detection, gridding and filtering), models of sea surface topography and tides, and the computational philosophies taken by each group [1].

In general, Sandwell's version 10.1 global grid is derived from multi-mission satellite altimetry from ERS-1, TOPEX, and GEOSAT, and refinements in filtering during gridding and Fourier transform conversion to procedures set out in [4]. To summaries, the along-track gradients (vertical deflection) were computed and gridded iteratively using splines that include Wiener-type filter. The gravity anomalies were computed from this grid using the Fourier transform implementation of the Laplacebased inversion of the vertical deflection method ([4]; Method 4 as mentioned above). However, these KMS grid have been computed using a combination of ERS-1 and GEOSAT satellite altimetry via geoids ([26], Method 2 as mentioned above).

\section{Results and Discussion}

\subsection{Free-Air Gravity Anomaly of the Study Area}

The marine gravity anomaly maps of the area investigated derived from satellite altimetry were seen to have a large gradient as a direct effect of bathymetric changes close to the coast. It had a very large gravity signal ranging between -120 and $90 \mathrm{mGal}$ (Figures 3-5). This major gravity signal was related to the Nile Deep Sea Fan, Levant Basin, Eratosthenes Seamount and Herodotus basin where steep bathymetric changes occurred within a few kilometers. The gravity field was seen to fall gradually just north to south of Nile Deep Sea Fan (Figures 3-5) where the depth rapidly grew to more than (-1500 meters) as shown in Figure 2. The qualitative analysis of the Free-air gravity anomalies reveals the following features:

- In the Nile Deep Sea Fan, Levant Basin, Eratosthenes Seamount and Herodotus basin, the altimetry Free-air gravity anomaly maps showed more local geological features related to tectonic settings and shallow structures. This information agreed also quite well with seismological activities in these regions [10].

- Free-air gravity anomaly map of the northern eastern of Nile Deep Sea Fan was generally characterized by negative Free-air gravity anomalies, with average values of about ( 0 to $90 \mathrm{mGal}$ ) in the continental margin area.

- The region of long linear features pointing at the Nile Deep Sea Fan, Sinai Peninsula coastlines and Levant Basin, corresponded to increasingly less negative Free-air gravity anomalies, with the only major positive anomaly in the marine areas situated over the mouth of the Nile Deep Sea Fan, owing to the load of the deltaic sediments.

- The Free-air anomaly described the state of isostatic equilibrium of a large-scale structure like a geological basin. It is very small if a region is totally compensated. The Free-air anomaly is positive if the structure is only partially compensated or not compensated at 
all. It is negative if the structure is over-compensated. The orientation of the Free-air anomalies in the study area indicated that the isostatic equilibrium was far from being achieved.

- The Free-Air anomaly map contains information on tectonic features at regional and local scale, which may reflect the effect of the bathymetric and topographic features in a very general way. There is an almost continuous concave negative anomaly pattern extending from the south of Herodotus abyssal plain to the northwest of the East Mediterranean Ridge.

- A comparison between the bathymetric and topographic features pattern map (Figure 2) and the FreeAir anomaly map (Figures 3-5) reveal many similarities. i.e. gradients of the Free-air anomalies are large in the vicinity of Levant Basin.
In order to evaluate the potentiality of the converted Free-air gravity anomaly as being representative of the gravity field, the qualitative analysis procedure of the potential anomalies, and comparison with an observed gravity map was made. A marine observed Bouguer gravity anomaly map of the studied region is available (B.G.I. and EGPC, 1980), and is given in Figure 6. Comparison between altimeter Free-air gravity and observed Bouguer anomaly maps showed good correlation in many locations. Some of these well-correlated locations can be summarized as:

- The Bouguer anomalies in the study area is dominated by an elongated NE-SW trending positive Bouguer anomaly, with a maximum of about $+200 \mathrm{mGal}$ coinciding with the elongated anomaly of the Herodotus Abyssal Plain.

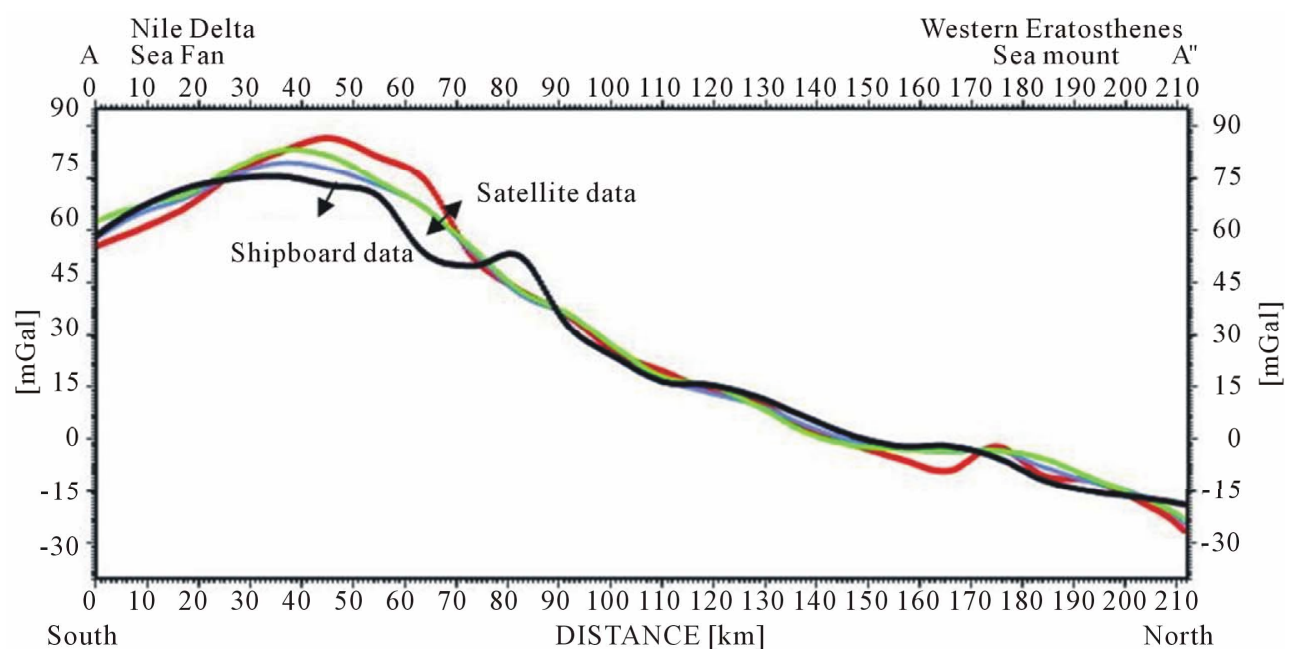

(a)

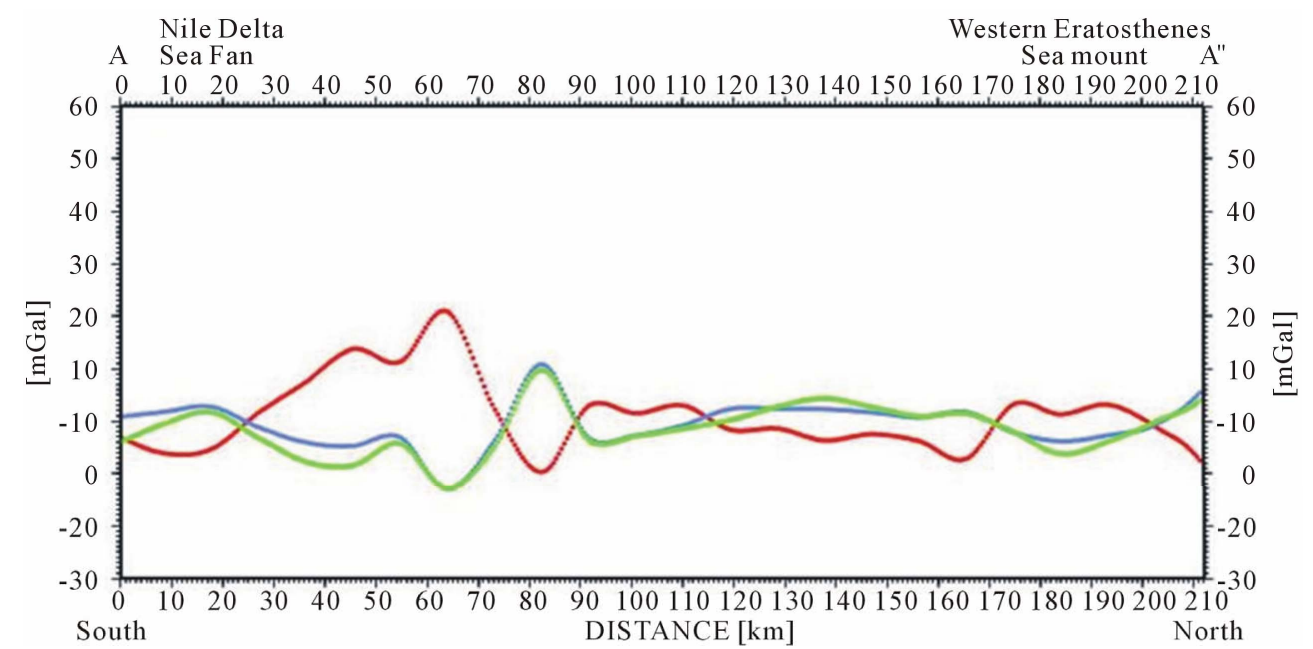

(b)

Figure 8. (a) A comparison of the shipborad gravity data with the satellite gravity data along profile A-A"; (b) The differnces between satellite and shipboard gravity data. The red curve desribes the satellite gravity data were obtained from Sandwell $e t$ al., 1997. The green and blue curves mark the KMS99 and KMS02 satellite gravity data were obtained from Andersen and Knudsen, 1998. 


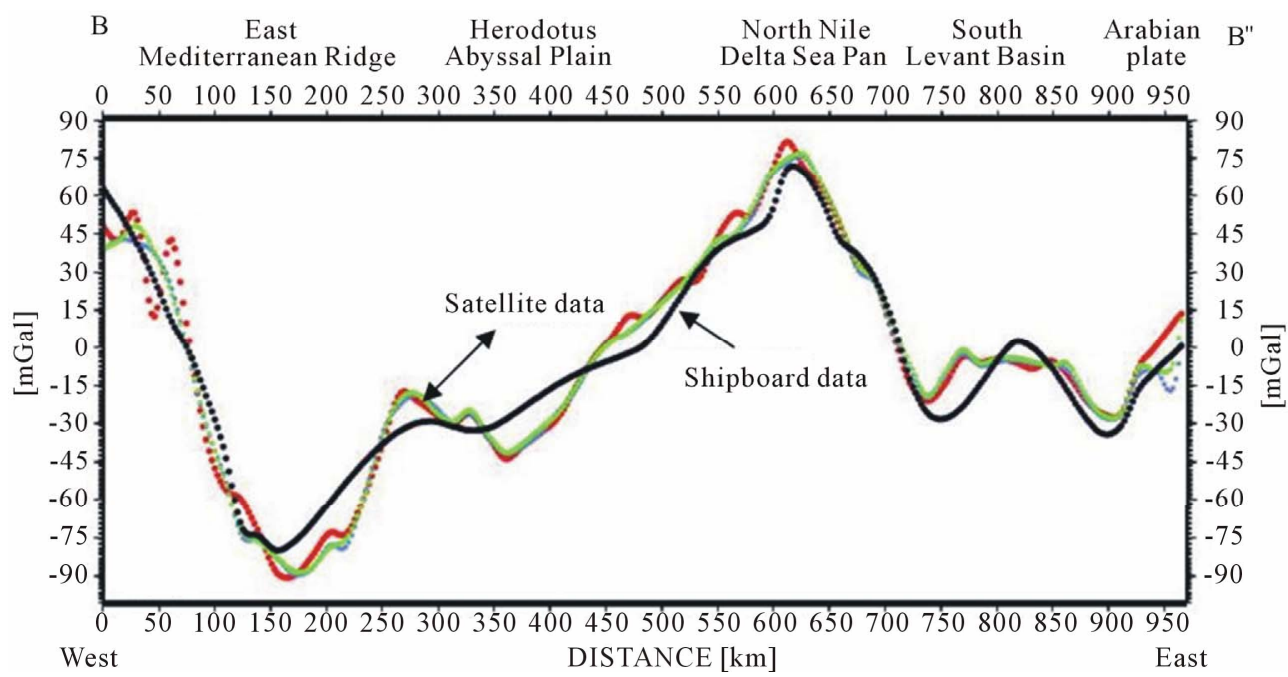

(a)

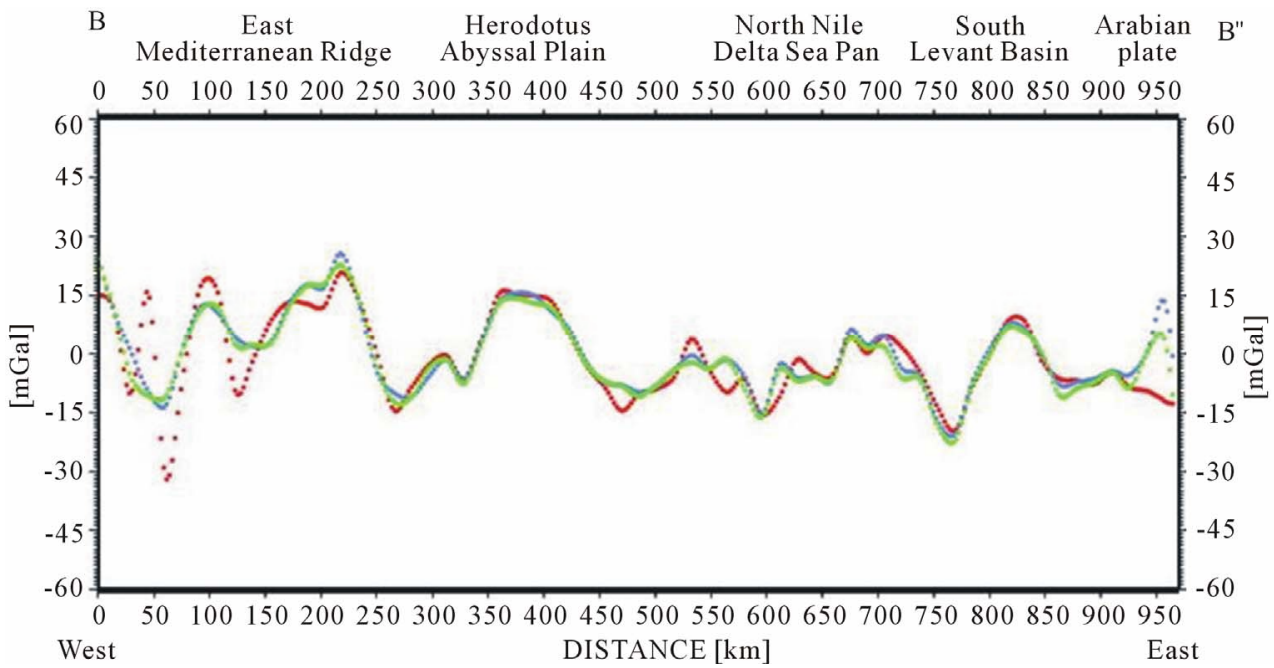

(b)

Figure 9. (a) A comparison of the shipborad gravity data with the satellite gravity data along profile B-B"; (b) The differnces between satellite and shipboard gravity data. The red curve desribes the satellite gravity data were obtained from Sandwell et al., 1997. The green and blue curves mark the KMS99 and KMS02 satellite gravity data were obtained from Andersen and Knudsen, 1998.

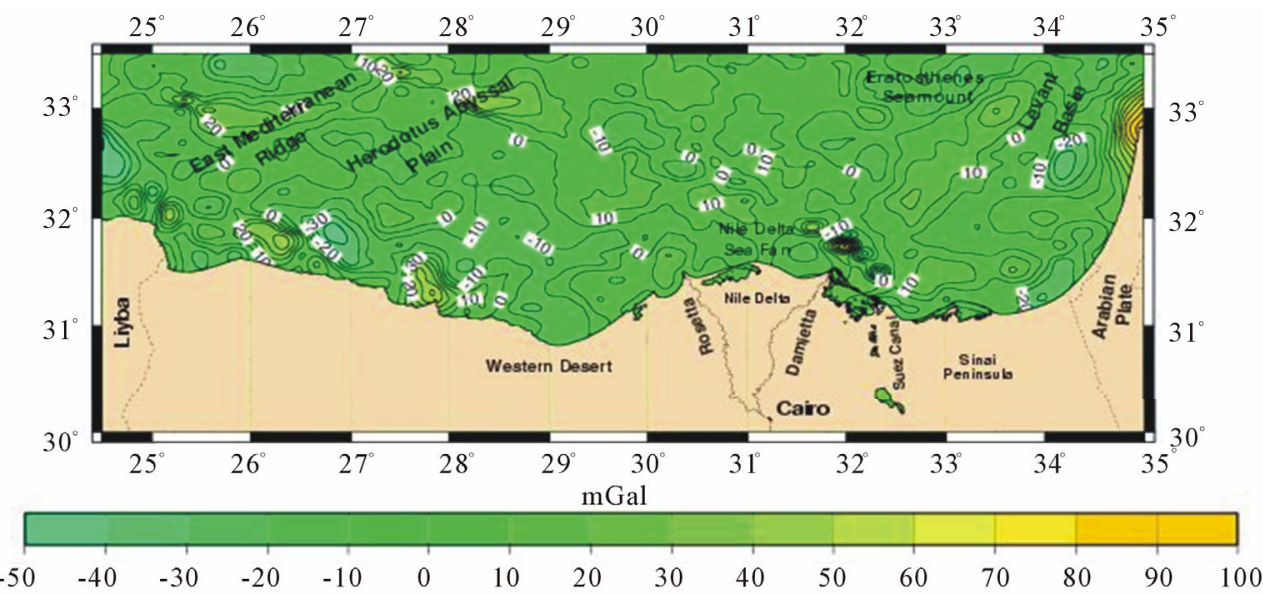

Figure 10. The differences between the Satellite data obtained from Sandwell et al., 1997 and shipboard gravity data. 
- Long linear anomalies in the study area were clear and well defined, being narrow and high gradient anomalies.

- Most of the broad changes in the Bouguer gravity anomalies can be related to changes in crust thickness. A relatively good correlation of the set of anomalies attributed to Nile Deep Sea Fan.

- The good correlation between altimeter Free-air gravity and the observed Bouguer anomaly data indicated that these data sets provide valuable information about marine subsurface structures and the gravity field.

\subsection{Comparison with the Shipboard Marine Free-Air Gravity}

As an example of estimating, and to show a comparison result of the shipboard gravity anomaly data of the area investigated and the satellite data, a comparison with the shipboard gravity anomaly data was made in two regions along two profiles (A-A" and B-B"). The regions belonging to these profiles had very different gravity signatures (Figures 3-5). Furthermore, these profiles crossed the main tectonic elements in the investigated area. The locations of the profiles are shown in Figures 3 and 7. In comparison with the shipboard gravity data, the satellite data showed only minor deviations in some partially regions of the area investigated (Figures 8 and 9). Also there were a significant dip and peak at all the gravity anomalies along the profiles A-A" and B-B"). However, the comparison of processed marine gravity data, and the resolution of satellite gravity data still seem to be limited. The major limitation of the satellite altimetry data was

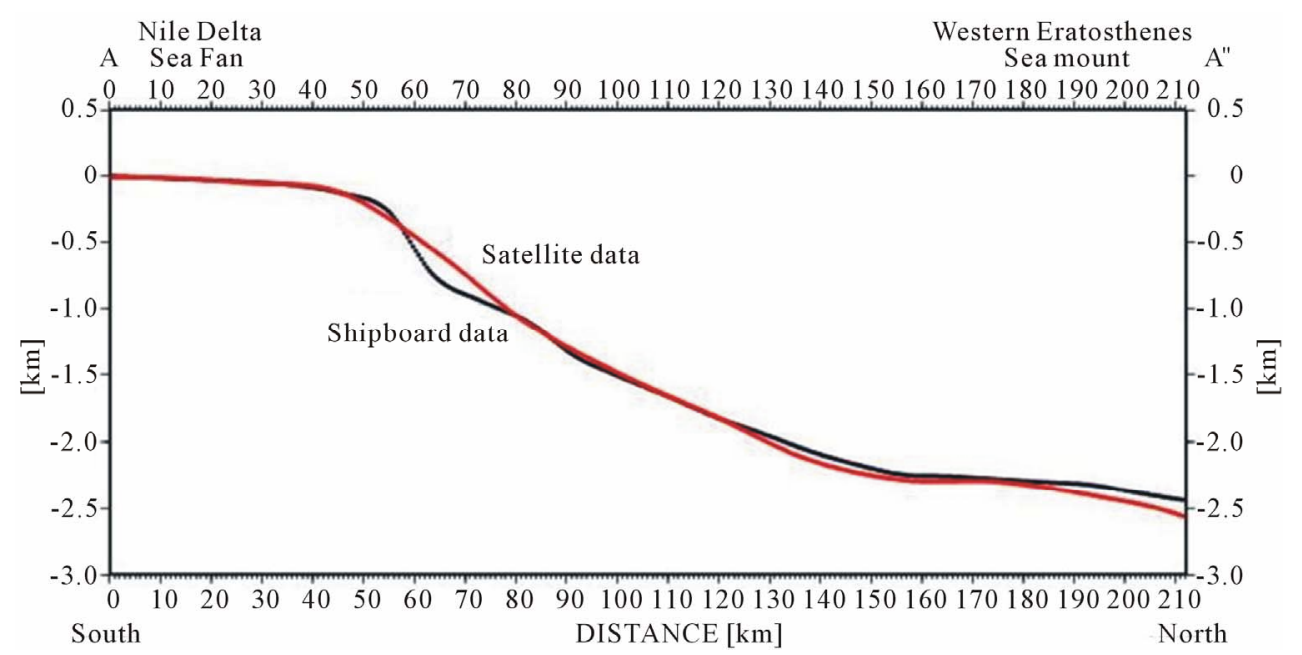

(a)

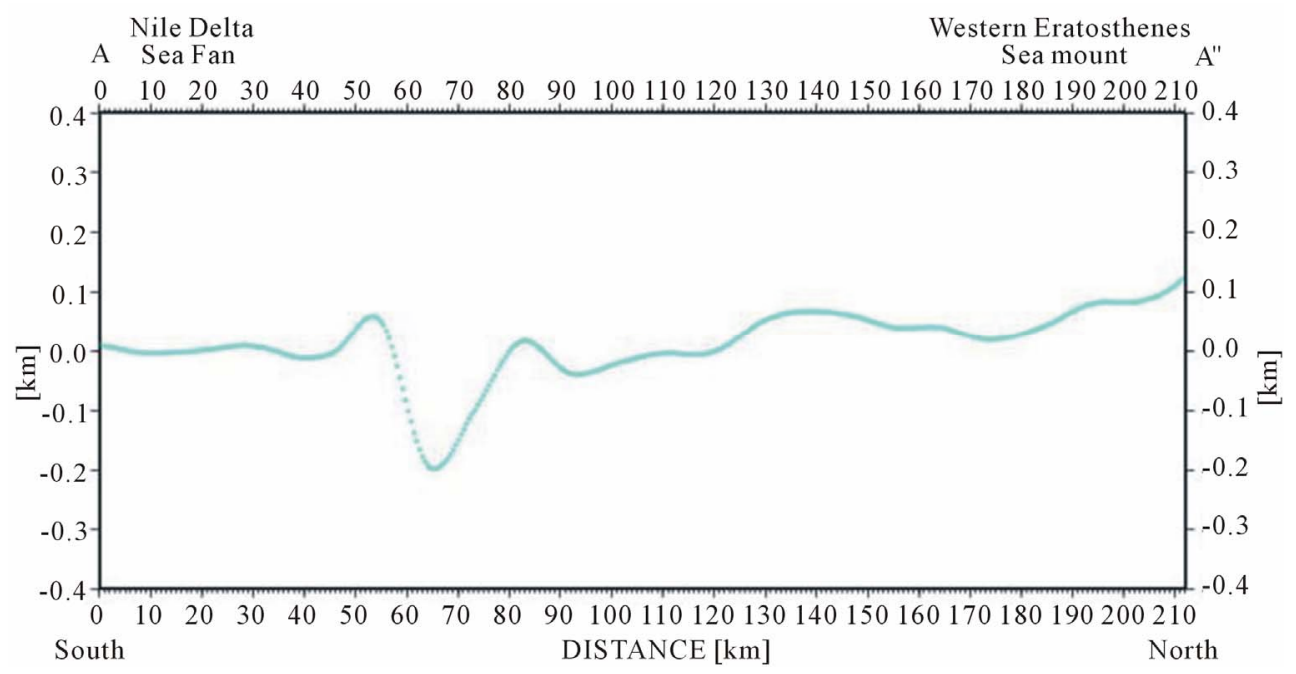

(b)

Figure 11. (a) A comparison of the shipboard bathymetric data with the bathymetric data provided by satellite altimetry; (b) The difference between satellite and shipboard data. This line represents profile A-A". (The satellite data were obtained from Sandwell et al., 1997). 
not of high precision but poor data coverage [27,29]. Also, in comparison with the wavelength gradient of the gravity anomaly, the long wavelength gradient could be observed and decreased in values towards the E-W direction. This behavior showed the edge-effect at the transition zone from oceanic to continental crust (Figures 3-5).

\subsection{The Differences between the Satellites-Shipboard Gravity Anomaly Data}

Figure 10 shows as an example the differences between the satellite and the shipboard data. This map was created by using the "grdmath" option in GMT software (Generic Mapping Tools, Wessel and Smith, 2001) for two grid files of the satellite and the shipboard gravity anomaly data. Some of features correlated locations can be summarized as:
- In general, the differences between the satellite and the shipboard data were small in some regions of the area investigated. These occurred mostly near to land. Furthermore, some strong deviations in some regions, which were spatially correlated with bathymetric depth and geological structures, became obvious from Figures 11 and 12.

- There were also differences in polarities and gradients of the gravity anomalies. These occurred mostly in regions of steep gravity gradients (i.e. in the northeast of Nile Deep Sea Fan) which reflected the impact of the structural features in the areas.

- A series of local maxima and minima of the gravity anomalies in areas near the Libyan and Egyptian coastlines may be related to young tectonic dislocations (Figure 9(a)).

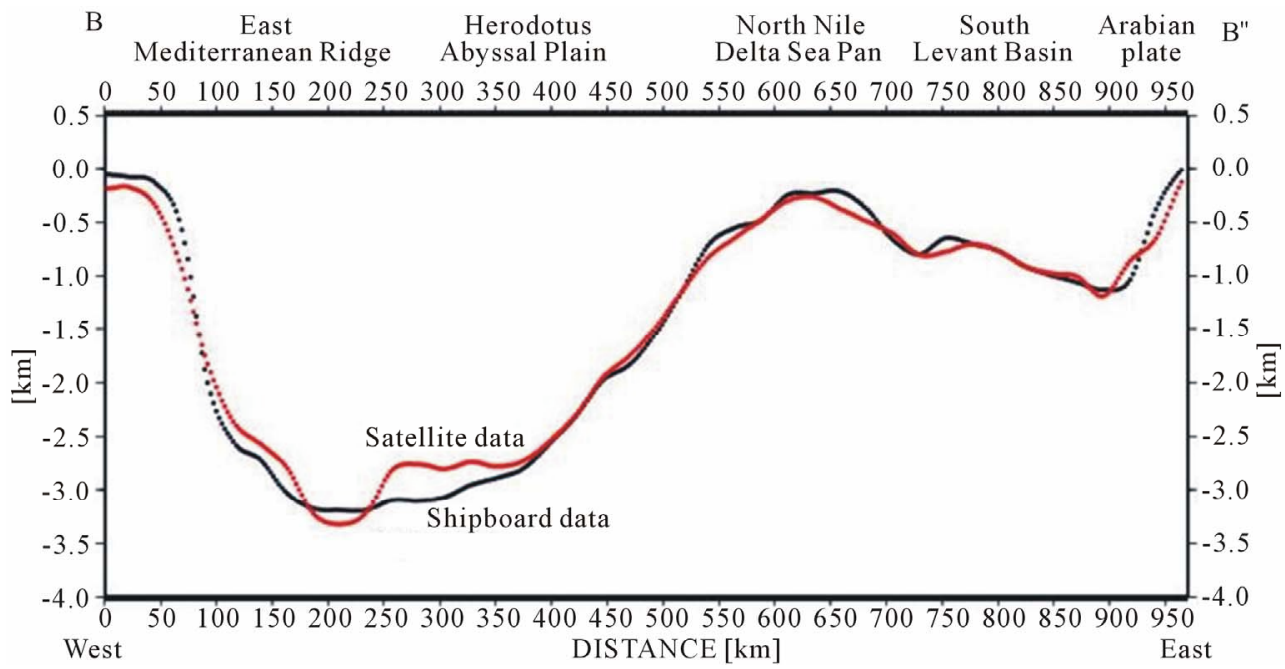

(a)

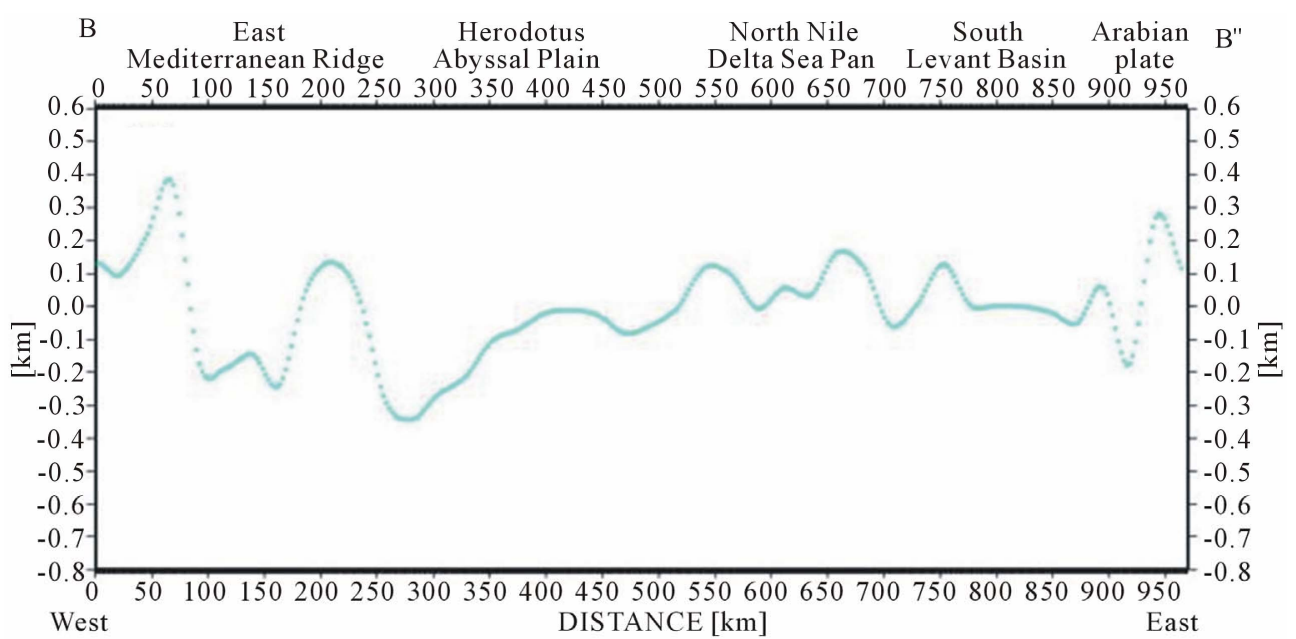

(b)

Figure 12. (a) A comparison of the shipboard bathymetric data with the bathymetric data provided by satellite altimetry; (b) The difference between satellite and shipboard data. This line represents profile B-B" (The satellite data were obtained from Sandwell et al., 1997). 
- Overall, the shipboard data were important to the coastal lines, the regions of strong bathymetric depths. However, the precision of the satellite data was sufficient when large scale features were studied.

\section{Conclusions}

This paper studied the potentiality of the altimeter data as a source of information serving the geophysical applications, a case study of the northern Egyptian continental margin. This study has been carried out by comparing of the shipboard gravity anomaly data and the satellite data. Free-air gravity anomaly map was also evaluated by comparing it to observed Bouguer gravity anomaly. Based on the results of the current study, the following conclusions can be made:

- The satellite marine altimetry gravity data showed a good correlation with the shipboard gravity anomaly data of the northern Egyptian continental margin and detects many small-scale bathymetry features.

- A good correlation has also been obtained between the altimeter Free-air gravity and the observed Bouguer anomaly data, which indicated that these data were able to figure out marine subsurface structures and gravity field.

- Generally, it can be stated that the satellite data offer additional and complementary data sets to help the geoscientists for determining the Earth's internal struure and tectonics. This provides valuable information of the Earth's gravity field.

\section{Acknowledgements}

Many Sincere thanks to Dr. Georeges Balmino and Mr. Gilles Balma, Bureau Gravity International data base (B.G.I.), Avenu Edourad Belin, France, for providing the on-offshore of geophysical field data on the study area. It is my pleasure to thank Prof. Dr. Ole B. Andersen, Senior Research Scientist, at the Kort and Matrikelstyreleson (National Survey and Cadastre), Geodetic Department, Copengham, Denmark for his help in providing KMS99, KMS02 satellite marine altimetry gravity data and bathymetry data necessary for the study area. Some of the figures have been generated using the Generic Mapping tool (GMT).

\section{REFERENCES}

[1] O. Andersen and P. Knudsen, "Global Gravity Field from the ERS-1 Geodetic Mission," Earth Observation Quarterly, Vol. 47, No. 45, 1995, pp. 1-5.

[2] G. Balmino, M. Moynot, M. Sarrailh and N. Vales, "Free Air Gravity Anomalies over the Oceans from Seasat and Geos3 Altimeter Data," EOS Transactions, Vol. 68, No. 2, 1987, pp. 17-18. doi:10.1029/EO068i002p00017
[3] W. Haxby, "Gravity Field of the Worlds Oceans: A Portrayal of Gridded Geophysical Data Derived from GEOSAT Rader Altimeter Measurements of the Shape of the Ocean Surface," Department of the US Navy, Office of Naval Research and NOAA Data Center, Boulder, 1987.

[4] D. Sandwell and W. Smith, "Marine Gravity Anomaly from Geosat and ERS-1 Satellite Altimetry," Journal of Geophysical Research, Vol. 102, No. B5, 1997, pp. 1003910054. doi:10.1029/96JB03223

[5] O. Andersen, P. Woodworth and R. Flather, "Intercomparison of Recent Global Ocean Tide Models," Journal of Geophysical Research, Vol. 100, No. C12, 1995, pp. 25261-25282. doi:10.1029/95JC02642

[6] L. Fu and A. Cazenave, "Satellite Altimetry and Earth Sciences: A Handbook of Techniques and Applications," International Geophysical Services, Academic Press, San Diego, Vol. 69, 2001, p. 463.

[7] R. Hipkin, "Modeling the Geoid and Sea-Surface Topography in Coastal Areas," Physics and Chemistry of the Earth, Vol. 25, No. 1, 2000, pp. 9-16. doi:10.1016/S1464-1895(00)00003-X

[8] A. El-Sayed, I. Korrat and H. Hussein, "Seismicity and Seismic Hazard in Alexandria (Egypt) and Its Surroundings," Pure and Applied Geophysics, Vol. 161, No. 5-6, 2004, pp. 1003-1019. doi:10.1007/s00024-003-2488-8

[9] H. Hussein, I. Korrat and A. El-Sayed, "Seismicity in the Vicinity of Alexandaria and Its Implication to Seismic Hazard," Proceedings of the 2nd International Symposium on Geophysics, Tanta, 19-20 February 2001, pp. 57-64.

[10] I. Korrat, N. El Agami, H. Hussein and M. El-Gabry, "Seismotectonics of the Passive Continental Margin of Egypt," Journal African Earth Science, Vol. 41, No. 1, 2005, pp. 145-150. doi:10.1016/j.jafrearsci.2005.02.003

[11] A. Aabdel Aal, J. Price, J. Vaitl and A. Shrallow, "Tectonic Evolution of the Nile Delta, Its Impact on Sedimentation and Hydrocarbon," 12th Petroleum Exploration and Production Conference, Cairo, 12-15 November 1994, pp. 19-34.

[12] Z. Ben-avraham, A. Nur and G. Cello, "Active Transcurrent Fault System along the North African Passive Margin," Tectonophysics, Vol. 141, No. 1-3, 1987, pp. 249260. doi:10.1016/0040-1951(87)90189-2

[13] V. Gaullier, Y. Mart, G. Bellaiche, J. Mascle, B. Vendeville and T. Zitter, "The Second Leg PRISMED II Scientific Party, 2000. Salt Tectonics in and around the Nile Deep-Sea Fan: Insights from PRISMED II Cruise,” In: B. Vendeville, Y. Mart and L. Vigneresse, Eds., Salt, Shale and Igneous Diapirs in and Around Europe, Vol. 174, Special Publications, Geological Society, London, 2000, pp. 111-129.

[14] J. Jackson and D. Mckenzie, "The Relationship between Plate Motions and Seismic Moment Tensors, and the Rates of Active Deformation in the Mediterranean and Middle East," Geophysical Journal, Vol. 93, No. 1, 1988, pp. 45-73. doi:10.1111/j.1365-246X.1988.tb01387.x

[15] L. Loncke, V. Gaullier, J. Mascle and B. Vendeville, 
"Shallow Structure of the Nile Deep Sea Fan: Interactions between Structural Heritage and Salt Tectonics; Consequences on Sedimentary Dispersal," CIESM Workshop Mediterranean and Black Sea Turbidite Systems and Deep Sea Fans, Bucharest, 5-8 June 2002.

[16] L. Loncke, V. Gaullier, J. Mascle, B. Vendeville and L. Camera, "The Nile Deep Sea Fan: An Example of Interacting Sedimentation, Salt Tectonics and Inherited Subsalt Paleotopographic Features," Marine Petrology and Geology, Vol. 23, 2006, pp. 297-315. doi:10.1016/j.marpetgeo.2006.01.001

[17] J. Lort, "The Tectonics of the Eastern Mediterranean: A Geophysical Review," Reviews of Geophysics and Space Physics, Vol. 9, No. 2, 1971, pp. 189-216. doi:10.1029/RG009i002p00189

[18] J. Mascle, C. Huguen and L. Loncke, "Evidences for Tectonic Reactivation along the African Continental Margins from Egypt to Libya," In: J. Mascle and F. Briand, Eds., African Continental Margins of the Mediterranean Sea, CIESM Workshop Series, Djerba, 22-25 November 2000, pp. 67-70.

[19] J. Mascle, J. Benkhelil, G. Bellaiche, T. Zitter, J. Woodside and L. Loncke, "The Prismed II Scientific Party (Including V. GAULLIER), Marine Geological Evidences for a Levantine-Sinai Plate, a Missing Piece of the Mediterranean Puzzle," Geology, Vol. 28, No. 9, 2000, pp. 779-782.

doi:10.1130/0091-7613(2000)028<0779:MGEFAL >2.3.C $\underline{\mathrm{O} ; 2}$

[20] D. Mckenzie, "Plate Tectonic of the Mediterranean Region," Nature, Vol. 226, No. 5242, 1970, pp. 239-243. doi: $10.1038 / 226239 \mathrm{a} 0$

[21] W. Mesherf, "Tectonic Framework of the Northern Egypt and Eastern Mediterranean Region," In: R. Said, Ed., The Geology of Egypt, A. A. Balkema, Rotterdam, 1990, pp. 113-153.

[22] A. Mosconi, A. Rebora, G. Venturino, P. Bocc and H. Khalil, "Egypt-Nile Delta and North Sinai Cenozoic Tectonic Evolutionary Model a Proposal," Proceedings of the 13th Egyptian General Petroleum Corporation Exploration and Production Conference, Cairo, Vol. 1, 21-24
October 1996, pp. 203-223.

[23] M. Schlumberger, "Well Evolution Conference," 1984, pp. 43-52.

[24] Sofratome Group, "Regional Geology, Tectonics and Seismology," Chapter 3, 1984, pp. 21-32.

[25] R. Ross and I. Uchupi, "The Structure and Sedimentary History of the SE Mediterranean Sea," Bulletin American Associations Petroume Geology, Vol. 61, 1977, pp. 879902.

[26] O. Andersen and P. Knudsen, "Global Marine Gravity Field from the ERS-1 and Geosat Geodetic Mission Altimetry," Journal of Geophysical Research, Vol. 103, No. C4, 1998, pp. 8129-8137. doi:10.1029/97JC02198

[27] D. Sandwell, "Antarctic Marine Gravity Field from High-Density Satellite Altimetry," Geophysical Journal International, Vol. 109, No. 2, 1992, pp. 437-448. doi:10.1111/j.1365-246X.1992.tb00106.x

[28] D. Sandwell and W. Smith, "Exploring the Ocean Basins with Satellite Altimeter Data," 1997.

http://topex.ucsd.edu/marine_grav/explore grav.html

[29] P. Knudsen and O. Andersen, "Global Marine Gravity and Mean Sea Surface from Multimission Satellite Altimetry," Geodesy on the Move, Gravity, Geoid, Geodynamics and Antarctica, Proceedings IAG Scientific Assembly, IAG Symposia, Springer, Berlin, 1998, pp. 132138.

[30] K. Lambeck, "Geophysical Geodesy: The Slow Deformation of the Earth," Oxford University Press, Oxford, 1988.

[31] W. Featherstone, "Comparison of Recent Satellite Altimeter-Derived Gravity Anomalies with One Another, EGM96 and Ship-Borne Gravimetry around Australia,' 2001.

http://www.cage.curtin.edu.au/ will/altimeter5.pdf

[32] W. Featherstone, J. Kirby, S. Holmes, G. Fotopoulos and J. Goos, "Recent Research towards an Improved Geoid Model for Australia," Joint Aurtian Institution Survey Conference, Adelaide, South Australia, 25-30 November 2002. 